\title{
Transcervical Transfer of Porcine Embryos under Practical Conditions
}

\author{
Isao YONEMURA, Yukihiro FUIINO'1), Seiichi IRIE and Yasutada MIURA \\ Tottori Swine and Poultry Experiment Station, Saihaku, Tottori 683-03, and \\ "Saitama Prefectural Livestock Experimental Station, Sugahiro, Kohnan-machi, \\ Saitama 360-01, Japan
}

\begin{abstract}
The aim of this study was to develop the transcervical method of pig embryo transfer using a rubber spiral catheter. A total of 587 ova and embryos were surgically collected on Days 4 to 6 (Day $0=$ onset of oestrus) from 36 donors, of which 456 transferable embryos were transcervically transferred to 25 synchronous ( 0 or \pm 1 day) recipients, without any premedical treatment, using a sterile rubber spiral catheter covered with a vinyl sheath. Embryos (the mean number \pm s.d. $=17.8 \pm 7.9$ ) were transferred to each recipient through the catheter with either $30 \mathrm{ml}$ or $50 \mathrm{ml}$ of phosphate buffered saline, which was supplemented with $0.4 \mathrm{mg} / \mathrm{ml}$ amikacin sulfate and $10 \%$ fetal calf serum, by the 2- or 3-stepwise method. Out of 25 recipients, 16 recipients became pregnant $(64 \%)$ and farrowed $(64 \%)$. The mean number of piglets farrowed ( \pm s.d.) was 3.1 \pm 1.6 , and the mean embryo survival rate ( \pm s.d.) was $16.7 \pm 7.6 \%$. No backflow was detected during and immediately after embryo transfer in any cases. The pregnancy and farrowing rates were $44 \%(4 / 9), 60 \%(6 / 10)$ and $100 \%(6 / 6)$ as they related to the combination of resistances to rotation of the catheter and to infusion of PBS with a syringe, $(+,+),(+,-)$ and $(-,-)$ in order, respectively. The insertion depth of the catheter in the case of $(-,-)$ was significantly larger $(P<0.01)$ than that in the cases of $(+,+)$ and $(+,-)$. No differences in the number of piglets farrowed and in the embryo survival rate were observed between the three combinations with respect to the resistance. The results indicated that a high pregnancy rate can be achieved by the transcervical transfer of pig embryos using a rubber spiral catheter when no resistances both in the rotation of catheter and infusion of fluid containing embryos are detected during embryo transfer. Key words: Transcervical transfer of embryos, Nonsurgical embryo transfer, Porcine embryos.
\end{abstract}

(J. Reprod. Dev. 42: 89-94, 1996)

A lmost 2 decades passed from the time when Polge and Day [1] reported a limited success in transcervical transfer of porcine embryos, until Sims and First [2] demonstrated a repeatable pregnancy in pigs using transcervical embryo transfer. Recently, Reichenbach et al. [3], Galvin et al. [4] and Hazeleger and Kemp [5] have obtained piglets derived from transcervical embryo transfers. The common factor for their successful transcervi-

Accepted for publication: January 19, 1996

Correspondence: I. Yonemura cal embryo transfers in pigs was apparently careful consideration for a deposit of embryos in the uterine lumen. Using concomitant infusions of large volumes of holding fluids, while transferring embryos may make it possible to transport embryos to a more appropriate location for survival in the uterine horns, because the tortuous and long uterine horns often preclude successful placement of embryos in the tip of the horns. Furthermore, using a sterile spiral catheter as a transfer instrument may improve the likelihood of depositing embryos in the lumen of the uterine horns and 
prevent damage and/or penetration of the cervical or uterine walls. The present study was conducted to perform transcervical transfer of pig embryos under more practical conditions than those published previously $[3,4]$, focusing on infusion with large volumes of transfer medium with the embryos, and using a spiral catheter as a transfer instrument without anesthetizing or tranquilizing recipients.

\section{Materials and Methods}

\section{Embryo collection}

Twenty-seven prepubertal 171-to 222-day-old crossbred gilts (LWD: Landrace $\times$ Large White $\times$ Duroc) and 10 175-to 267-day-old Landrace gilts were used as donors. They were administered intramuscularly with 1,000 to 1,500 I.U. of pregnant mare's serum gonadotrophin (PMSG, Serotropin, Teikoku Hormone MFG. Co. Ltd., Tokyo, Japan) followed $72 \mathrm{~h}$ later by 500 to 750 I.U. of human chorionic gonadotrophin (hCG, Gonatropin, Teikoku Hormone MFG. Co. Ltd.). The donors were inseminated at 24,36 and $48 \mathrm{~h}$ after the injection of the hCG. Embryos were recovered on Days 4 to 6 of the oestrous cycle (Day $0=$ onset of oestrus) by surgically flushing their uteri via a midventral incision using general anesthesia with oxygen and halothane. Each ovary and uterine horn was exteriorized and the number of corpora lutea were recorded. A balloon catheter (French size $=18$ ) was inserted through an incision made at the cervical end of the uterine horn and the whole uterine horn was flushed in a retrograde fashion with $50 \mathrm{ml}$ of Dulbecco's phosphate buffered saline (PBS, Nissui Pharmaceutical Co. Ltd., Tokyo, Japan) warmed at $38 \mathrm{C}$ containing penicillin (100 I.U./ml), streptomycin sulfate $(50 \mu \mathrm{g} / \mathrm{ml})$ and $0.1 \%$ bovine serum albumin (BSA fraction V, Sigma, St. Louis, MO, USA). The flushings were recovered into sterile $100 \mathrm{ml}$ glass tubes. The uterine horns and ovaries were returned to the peritoneal cavity and the incision was closed with 4 layers of sutures. Embryos were recovered under a stereomicroscope and developmental stage and normality were morphologically evaluated. They were stored at $37 \mathrm{C}$ in air in PBS containing penicillin (100 I.U./ ml), streptomycin sulfate $(50 \mu \mathrm{g} / \mathrm{ml})$ and $20 \%$ fetal calf serum [6] for 2 to $20 \mathrm{~h}$ until they were transferred to recipients. Unfertilized ova and morphologically abnormal embryos were not used for transfer.

\section{Embryo transfer}

Twenty prepubertal crossbred LWD gilts, 160 to 198 days old, and 5 sows, 321 to 339 days old, were used as recipients. The immature gilts underwent the same PMSG and hCG regimen at the same time as the donors (synchronous) or the following day ( -1 day asynchronous) with one exception ( +1 day asynchronous). The sows were similarly treated on the first day of weaning. The recipients were not anesthetized or tranquilized prior to embryo transfer. One or 2 people prevented each recipient from moving by supporting her from the sides. The vulva and the surroundings of each recipient were cleaned with alcohol cotton and rinsed with sterilized PBS. A sterile rubber spiral catheter generally used for artificial insemination (FA1454, Fujihira Equipments and Instruments Co. Ltd., Tokyo, Japan), covered with a vinyl sheath used for bovine embryo transfer (ZA060, IMV, L'Aigle, France), was introduced into the cervical opening through the vagina, and then inserted into the cervix by turning it counterclockwise until firmly in place where it could not advance further. A $50 \mathrm{ml}$ plastic syringe containing PBS supplemented with $0.4 \mathrm{mg} / \mathrm{ml}$ amikacin sulfate (Banyu Pharmaceutical Co. Ltd., Tokyo, Japan) and $10 \%$ fetal calf serum (the infusion fluids) was secured to the end of the catheter, and the PBS was infused into the reproductive tract through the catheter. Unless any backflow occurred,the following 2 methods were alternatively attempted. The pre-infusion was always with $20 \mathrm{ml}$ when Method A was used and with $10 \mathrm{ml}$ or $20 \mathrm{ml}$ when Method B1 or Method B2 was used, respectively. 1) Method A: A 50 ml-capacity plastic syringe containing embryos with $30 \mathrm{ml}$ of the infusion fluids was attached to the end of the catheter. The infusion fluids containing embryos were inserted through the catheter into the genital tract. 2) Method B: A 2.5 ml-capacity plastic syringe containing embryos in $2 \mathrm{ml}$ of the infusion fluids was connected with the catheter by a 3-way stopcock (TS-TL1K, Terumo. Co. Ltd., Tokyo, Japan). Embryos in the infusion fluids were expelled, and then flushed into the reproductive tract either with 18 $\mathrm{ml}$ (Method B1) or with $28 \mathrm{ml}$ (Method B2) of the infusion fluids using a $50 \mathrm{ml}$-capacity syringe attached to the other end of the stopcock. At embryo transfer, it was recorded whether or not there was 
resistance to counterclockwise rotation of the catheter and to infusion of PBS solution containing embryos. The length of the catheter left outside of the vulva was also recorded. A counter flow or leakage of transfer medium was checked during and after embryo transfer. In both methods, $10 \mathrm{ml}$ of atmospheric air in a syringe was used to purge the fluids from the catheter into the genital tract. After 1 minute of injection with air, the insemination catheter was withdrawn by turning clockwise observing for any remaining fluid in the catheter. Any residual fluid left in the catheter was flushed into a petri dish and examined under a stereomicroscope for any remaining embryos. Recipient pigs were monitored daily for return to estrus. Females not returning to estrus were examined for pregnancy using Preg-Tone (Renco Corporation, USA) between day 30 to 60 after estrus. Pregnant recipients were allowed to carry their pregnancies to term.

\section{Statistical analysis}

Differences in the percentage of pregnancy and the embryo survival rate, which were sorted by whether or not there were the resistances to counterclockwise rotation of the catheter and to infusion of PBS solution containing embryos, were evaluated using Fisher's exact test. Differences in the number of embryos transferred, the number of piglets farrowed and the length of the catheter left outside of the vulva were assessed using Student's $t$-test after performing a logarithmic transformation. $\mathrm{P}<0.05$ denoted significance.

\section{Results}

The distribution of the developmental stages of 456 embryos was follows: 4-cell embryos (1.3\%), 8cell embryos $(3.5 \%)$, morulae $(14.5 \%)$, early blastocysts $(24.1 \%)$, blastocysts $(25.2 \%)$, expanded blastocysts (16.9\%) and hatched blastocysts (14.5\%). The transfer data for each recipient are summarized in Table 1. Twenty-five transcervical transfers were performed. The mean number of embryos used for transfer was $18.2 \pm 7.7$. Because some embryos remained in the transfer instrument without entering to the genital tract, the mean actual number of embryos transferred to each recipient was $17.8 \pm 7.9$. Sixteen recipients became pregnant and farrowed (64\%). Among the 16 recipients that carried embryos to term, $16.7 \pm 7.6 \%$ of the embryos transferred produced live births. The average number of piglets farrowed was $3.1 \pm 1.6$. It appeared that more litters were farrowed as more embryos were transferred; the number of piglets farrowed was significantly higher in recipients receiving more than 20 embryos than in those receiving 10 to 14 embryos $(\mathrm{P}<0.05)$.

Backflow of PBS was not detected during and immediately after infusion of PBS with embryos in any cases. The pregnancy and farrowing rates were $44 \%(4 / 9), 60 \%(6 / 10)$ and $100 \%(6 / 6)$ as they related to the combination of resistances to rotation of the catheter and to infusion of PBS with a syringe, $(+,+),(+,-)$ and $(-,-)$ in order, respectively (Table 2$)$. The insertion depth of the catheter in the case of $(-,-)$ was significantly larger $(\mathrm{P}<0.01)$ than that in the cases of $(+,+)$ and $(+,-)$. No differences in the number of piglets farrowed and in the embryo survival rate were observed between the three combinations with respect to resistance.

\section{Discussion}

The pregnancy rates and farrowing rates in the present study attained $64 \%(16 / 25)$, while Reichenbach et al. [3] and Galvin et al. [4] reported a 10\% $(6 / 58)$ pregnancy rate and a $22 \%(10 / 46)$ farrowing rate, respectively. One of the speculative reasons why the relatively high rates of pregnancy and farrowing were obtained in the present study was because a larger volume of fluids containing embryos was infused into the reproductive tract of each recipient. Reichenbach et al. [3] and Galvin et al. [4] infused 10 to $12 \mathrm{ml}$ of fluids containing embryos. According to Galvin et al. [4], backflow of medium out of the vulva was observed from the spirette containing either 30 or $60 \mathrm{ml}$ of medium following flushing, and no pregnancies were established in those gilts. In the present study, at least during and just after infusion, no backflow of the infused fluids out of the vulva was observed even when $50 \mathrm{ml}$ of fluids was infused. The cause of this difference was not clear. However, when the relationship between the volume of semen and pregnancy rate following insemination was examined, higher pregnancy rate was obtained by infusion of $50 \mathrm{ml}$ of semen than with 10 to $20 \mathrm{ml}$ of semen [7]. This suggested that the more volume 
Table 1. Results of transcervical embryo transfer in pigs

\begin{tabular}{|c|c|c|c|c|c|c|c|c|}
\hline $\begin{array}{l}\text { Method of } \\
\text { infusion }{ }^{1}\end{array}$ & $\begin{array}{l}\text { Embryonic } \\
\text { stage }\end{array}$ & $\begin{array}{l}\text { Age of } \\
\text { embryo } \\
\text { in days }\end{array}$ & $\begin{array}{l}\text { Synchrony of } \\
\text { recipients }\end{array}$ & $\begin{array}{l}\text { No.of } \\
\text { Embryos } \\
\text { transferred } 2\end{array}$ & Pregnancy & $\begin{array}{l}\text { No. of } \\
\text { piglets } \\
\text { farrowed }\end{array}$ & $\begin{array}{l}\text { Embryo } \\
\text { survival, } \\
(\%)\end{array}$ & $\begin{array}{l}\text { Depth of } \\
\text { catheter, } \\
(\mathrm{cm})\end{array}$ \\
\hline A & $M \sim B$ & 5 & 0 & 23 & - & & & 30 \\
\hline A & $M \sim B$ & 5 & 0 & 21 & + & 4 & 19.0 & 42 \\
\hline A & $\mathrm{M} \sim \mathrm{B}$ & 6 & 0 & 43 & + & 5 & 11.6 & 38 \\
\hline $\mathrm{A}$ & $\mathrm{M} \sim \mathrm{EB}$ & 6 & -1 & 35 & + & 7 & 20.0 & 25 \\
\hline A & $\mathrm{eB} \sim \mathrm{B}$ & 5 & -1 & 18 & + & 4 & 22.2 & 28 \\
\hline $\mathrm{A}$ & $\mathrm{eB} \sim \mathrm{HB}$ & 5 & 0 & 25 & - & & & 25 \\
\hline $\mathrm{A}$ & $\mathrm{B} \sim \mathrm{HB}$ & 6 & -1 & 15 & - & & & 21 \\
\hline $\mathrm{A}$ & $\mathrm{B} \sim \mathrm{HB}$ & 6 & 0 & 27 & + & 2 & 7.4 & 35 \\
\hline B1 & $8 \sim \mathrm{M}$ & 4 & -1 & 14 & + & 2 & 14.3 & 23 \\
\hline B1 & $8 \sim \mathrm{eB}$ & 4 & 0 & 14 & + & 3 & 21.4 & 25 \\
\hline B1 & $\mathrm{eB} \sim \mathrm{B}$ & 5 & -1 & 16 & - & & & 30 \\
\hline B1 & $\mathrm{eB} \sim \mathrm{B}$ & 5 & -1 & 14 & + & 1 & 7.1 & 33 \\
\hline B1 & $\mathrm{eB} \sim \mathrm{B}$ & 5 & +1 & 16 & - & & & 28 \\
\hline B1 & $\mathrm{B} \sim \mathrm{HB}$ & 5,6 & $-1,0$ & 13 & + & 2 & 15.4 & 27 \\
\hline B2 & $4 \sim \mathrm{M}$ & 4 & 0 & 14 & + & 1 & 7.1 & 28 \\
\hline B2 & $\mathrm{M} \sim \mathrm{B}$ & 5 & -1 & 14 & - & & & 29 \\
\hline B2 & $\mathrm{eB} \sim \mathrm{B}$ & 5 & -1 & 17 & + & 3 & 17.6 & 25 \\
\hline B2 & $\mathrm{eB} \sim \mathrm{B}$ & 5 & -1 & 19 & - & & & 27 \\
\hline B2 & $\mathrm{eB} \sim \mathrm{B}$ & 5 & -1 & 12 & + & 2 & 16.7 & 33 \\
\hline B2 & $\mathrm{eB} \sim \mathrm{B}$ & 5 & -1 & 12 & + & 4 & 33.3 & 33 \\
\hline B2 & $\mathrm{B} \sim \mathrm{HB}$ & 6 & -1 & 13 & + & 3 & 23.1 & 21 \\
\hline B2 & $\mathrm{EB} \sim \mathrm{HB}$ & 6 & -1 & 9 & - & & & 25 \\
\hline B2 & $\mathrm{EB} \sim \mathrm{HB}$ & 6 & -1 & 7 & - & & & 24 \\
\hline B2 & $\mathrm{EB} \sim \mathrm{HB}$ & 6 & -1 & 15 & + & 4 & 26.7 & 33 \\
\hline B2 & $\mathrm{B} \sim \mathrm{HB}$ & 6 & -1 & 19 & + & 2 & 10.5 & 37 \\
\hline
\end{tabular}

${ }^{1)} \mathrm{A}$ indicates a method by which embryos were directly infused using a $50 \mathrm{ml}$ plastic syringe, (the amount of fluid was $50 \mathrm{ml}$ ). B1 indicates a method by which embryos were infused through a 3-way stopcock, (the amount of fluid was $30 \mathrm{ml}$ ). B2 indicates a method by which embryos were infused through a 3-way stopcock, (the amount of fluid was $50 \mathrm{ml}$ ).

${ }^{2}$ The net number of embryos transferred, that is the number before transfer minus the number of embryos found in the catheter or the instrument after transfer.

Table 2. Transcervical pig embryo transfer results with respect to catheter rotation and PBS infusion resistance

\begin{tabular}{|c|c|c|c|c|c|c|}
\hline \multirow{2}{*}{$\begin{array}{l}\text { Combination } \\
\text { of resistance }^{1}\end{array}$} & \multicolumn{2}{|c|}{ No. of recipients } & \multirow{2}{*}{$\begin{array}{l}\text { Mean no. } \\
\text { of embryos } \\
\text { transferred }\end{array}$} & \multirow{2}{*}{$\begin{array}{l}\text { Mean } \\
\text { litters size } \\
\text { farrowed }\end{array}$} & \multirow{2}{*}{$\begin{array}{c}\text { Embryo } \\
\text { survival, } \\
\%\end{array}$} & \multirow{2}{*}{$\begin{array}{l}\text { Depth of } \\
\text { catheter, cm }\end{array}$} \\
\hline & $\begin{array}{l}\text { transferred } \\
\text { embryos }\end{array}$ & $\begin{array}{l}\text { became } \\
\text { pregnant }(\%)\end{array}$ & & & & \\
\hline,++ & 9 & $4(44.4)$ & $18.2 \pm 8.36^{2}$ & $3.3 \pm 2.63$ & $16.4 \pm 6.96$ & $25.9 \pm 3.92^{b}$ \\
\hline,+- & 10 & $6(60.0)$ & $14.2 \pm 2.70$ & $3.0 \pm 0.89$ & $20.9 \pm 6.74$ & $27.9 \pm 3.45^{b}$ \\
\hline,-- & 6 & $6(100.0)$ & $23.3 \pm 10.77$ & $3.0 \pm 1.55$ & $13.7 \pm 7.68$ & $36.3 \pm 3.44^{\mathrm{a}}$ \\
\hline
\end{tabular}

1) Resistance to rotation of the catheter, resistance to infusion of PBS with a syringe.

2) Values are mean \pm standard deviation.

a, b Signifficantly different $(\mathrm{P}<0.01)$, Student's $t$-test after log-transformation.

of semen infused, the more efficiently the semen could travel to the tip of the uterine horn. Furthermore, the most appropriate location of surgical and endoscopic embryo transfer in swine has been reported to be from the tip to the middle part of the uterine horn [8]. In fact research was shown it was impossible to obtain pregnant pigs by surgical transfer of embryos at the end of the uterine horn (Hayashi, personal communication) and at the uterine body (our unpublished data). Therefore, it would be reasonable to consider that the infusion of embryos with larger volume of medi- 
um increased the opportunity of transporting embryos to the middle part or to the tip of the uterine horn. In the present study, no differences in pregnancy rate and embryo survival were observed between $30 \mathrm{ml}$ and $50 \mathrm{ml}$ of infusion fluid.

The spirette was covered by a vinyl sheath until it was inserted into the cervical canal of each recipient. Amikacin sulfate, which has a special sensitivity against bacteria from boar's semen [9], was supplemented in the infusion fluids. These aseptic precautions taken in this transcervical embryo transfer study may have resulted in the relatively high pregnancy and farrowing rates. Hazeleger and Kemp [5] also obtained high pregnancy rate following transcervical transfer of porcine embryos when the transfer instrument was protected by a polyethylene sheet until reaching approximately halfway through the cervix.

The mean litter size and embryo survival through farrowing were $3.1 \pm 1.6$ and $16.7 \pm 7.6 \%$ in the present study. In previous reports, mean litter size and embryo survival through farrowing were 5.2 \pm 2.6 and $17 \%$ [3] and $4.3 \pm 0.7$ and $35.6 \%$ [4]. Hazeleger and Kemp [5] reported $6.7 \pm 1.6$ as litter size and $37 \%$ as embryo survival. The result obtained for litter size in the present study was significantly lower $(\mathrm{P}<0.05$ and $\mathrm{P}<0.01$, respectively) than the results obtained by Galvin et al. [4], and by Hazeleger and Kemp [5]. Similarly, the result for embryo survival in the present study was lower $(\mathrm{P}<0.01)$ than the results obtained by Galvin et al. [4], and by Hazeleger and Kemp [5]. The litter size and the embryo survival after the transcervical embryo transfer were significantly lower than those after surgical embryo transfer $[4,10]$. In the current study's preliminary experiments, the surgical transfer farrowing rate was $79 \%(11 / 14)$, the mean litter size was $7.4 \pm 3.2$, and developmental rate of embryos to term was $66.6 \pm 12.5 \%$ (data not shown). Although the precise cause of the low survival was obscure, one possible interpretation might be that the location of embryos deposited and distributed in the uterine horn was not suitable for survival. This speculation also might mean that transferred embryos were dis- charged from the uterus to the vaginal cavity through the cervix, even when no backflow of infusion fluids was observed during and immediately after embryo transfer. Pregnancy rates were higher when larger amounts (30 to $50 \mathrm{ml}$ ) of fluids were infused with embryos than when 10 to $12 \mathrm{ml}$ was infused as demonstrated by Reichenbach et al. [3] and Galvin et al. [4]. However, Hazeleger and Kemp [5] obtained high pregnancy rates and large litter sizes when embryos were injected into the uterine body in $0.1 \mathrm{ml}$ transfer medium. Any adverse effect of infusion with large amounts of medium on embryo survival will need to be clarified.

In the present study, when no resistances of counterclockwise rotation and infusion of PBS by a syringe were detected, the pregnancy and farrowing rates were $100 \%(6 / 6)$. On the other hand, when any resistance was detected, the pregnancy and farrowing rates significantly $(\mathrm{P}<0.05)$ decreased to $52.6 \%(10 / 19)$. These results suggested that a lack of resistance was an indication that the tip of the catheter reached the uterine body and allowed a reliable deposit of embryos in the uterine body.

In conclusion, it was evident that the location of the tip of the catheter affected the establishment of pregnancy through transcervical transfer of pig embryos. Successful transcervical transfer depends on reliably depositing embryos in the uterus. The present study demonstrated a transcervical transfer of porcine embryos with a spiral catheter as a transfer instrument without anesthetizing or tranquilizing the recipients. Further studies are required to elucidate the cause of the low litter size.

\section{Acknowledgments}

The authors wish to acknowledge the critical review and the editing of the manuscript by Drs. Toshiyuki Kojima and Chris O'Neill. They also thank the staff of Tottori Prefecture Meat Inspecting Office for their cordial collaborations. 


\section{References}

1. Polge C, Day BN. Pregnancy following non-surgical egg transfer in pigs. Vet Rec 1968; 82: 712.

2. Sims MM, First NL. Nonsurgical embryo transfer in swine. Journal of Animal Science 1987; 65 (Suppl. 1): 386 (Abstr).

3. Reichenbach HD, Modl J, Brem G. Piglets born after transcervical transfer of embryos into recipient gilts. Vet Rec 1993; 133: 36-39.

4. Galvin JM, Killian DB, Stewart ANV. A procedure for successful nonsurgical embryo transfer in swine. Theriogenology 1994; 41: 1279-1289.

5. Hazeleger W, Kemp B. Farrowing rate and litter size after transcervical embryo transfer in sows. Reprod Dom Anim 1994; 29: 481-487.

6. Blum-Rekow B, Holtz W. Transfer of porcine embryo after 3 days of in vitro culture. J Anim Sci
1991; 69: 3335-3342.

7. Self HL. A.I. in swine-Where are we ? In: Roberts SJ (ed.), Veterinary Obstetrics and Genital Diseases (Theriogenology) 1991; Edwards Brothers, Michigan.

8. Stein-Stefani J, Holtz W. Surgical and endoscopic transfer of porcine embryos to different uterine sites. Theriogenology 1987; 27: 278 (Abstr).

9. Sone M, Bamba K, Ohmura K. Effects of various antibiotics on the control of bacteria in boar semen. Vet Rec 1982; 111: 11-14.

10. Polge C. Embryo transplantation and preservation. In: DJA Cole, GR Foxcroft (eds.), Control of Pig Reproduction. Butterworth, London; 1982; 277-291. 